\title{
Un diagnóstico político para El Salvador, 2001
}

\author{
- Álvaro Artiga-Gonzólez
}

\section{El trabajo previo de la comisión que elaboraría el diagnóstico}

El pasado mes de julio del año en curso, la Universidad Centroamericana José Simeón Cañas (UCA) realizó el seminario Ejes de acción, para el cual se conformó una comisión multidisciplinar con docentes de varias unidades académicas y a la cual se le encargó la elaboración de un diagnóstico de la realidad salvadoreña que sirviera de encuadre para la definición de los ejes de acción que han de hacer posible la Misión de la UCA. Producto de varias discusiones previas al seminario, esta comisión definió un "Marco global condicionante de la realidad nacional" sobre la hase de procesos o dinámicas globales desde el punto de vista de la economía, la política, la sociedad, la cultura, la ciencia y tecnología y el medio ambiente. De común acuerdo, se buscaría la manifestación local de estas dinámicas globales para ser presentadas al pleno de los asistentes al seminario.' Personalmente, considero que el trabajo realizado en las sesiones de la comisión lue muy enriquecedor, por cuanto parecíamos estar armando una fotografía con piezas que provenían de diversas disciplinas. Este hecho generaba tensiones entre optar conscientemente por un enfoque multidisciplinar o por uno interdisciplinar. Fácilmente parecíamos deslizarnos hacia una contribución personal desde la propia disciplina para luego simplemente yuxtaponerlas incluso en una tabla resumen dividida justamente según la disciplina académica en la que cada uno se desenvuelve.

Desde mi punto de vista, en la presentación del trabajo de la comisión predominó lo multidisciplinar. De hecho, cada uno contó con aproximadamente veinte Ininutos para hacer su presentación centrada en su especialidad. No obstante, creo que en los trabajos previos las discusiones mostraban atisbos de inter- 
disciplinariedad. Para mí era un gusto ver y escuchar dialogar a ingenieros con cientistas sociales y filósofos; ${ }^{2}$ la mayoría, tratando de ver con los lentes del otro lo que no ppdía ver con los propios. Personalmente, lamento que en esta comisión no hubiesen mujeres. Creo que su participación hubiese enriquecido aún más el trabajo. Sin embargo, ya esta ausencia al interior mismo de la comisión nos sugería un dato de las dinámicas que tratábamos de definir: la exclusión que sufren las mujeres todavía en pleno siglo XXI. Particularmente, considero que un Eje de acción para la Misión de la UCA pasa por un mayor protagonismo femenino en su interior.

Una vez definido el Marco global condicionante de la realidad nacional, se nos pidió a cada uno de los miembros de la comisión identificar su manifestación local. Esto se haría desde la especialidad de cada uno y luego se haría una puesta en común para recibir aportes de los otros miembros. Al proceder con csta lógica, se había privilegiado lo global sobre lo local. Se reconocía entonces el peso condicionante de los procesos globales para cualquier alternativa de acción local. ' Lo cual no significa que lo exterior determine lo interior. O, que en términos nacionales, no podamos hacer nada frente a lo que nos viene de fuera. Es, más bien, reconocer que lo global ya está aquí como algo local. Esta manera de hablar nos permite comprender por qué podemos actuar localmente con fines globales. En definitiva, nos permite imaginar acciones locales con sentido global ${ }^{4}$. Si, por ejemplo, los Estados Unidos adoptaran el protocolo de Kyoto, esa acción local (en tanto disminución local de las emulsiones contaminates del medio ambiente) tendría efectos globales al reducir o, detener al menos, el calentamiento del planeta.

\section{El diagnóstico político}

Particularmente, se me encargó la tarea de definir las dinámicas o procesos políticos del diagnóstico. Con tal fin, tomé en cuenta las discusiones previas para identificar las manifestaciones políticas del Marco global condicionante. Junto a estas manifestaciones globales intenté definir lo que serían sus manifestaciones locales. Es decir, la traducción local de procesos políticos globales. El Cuadro 1 muestra estas dos dimensiones para cada uno de los procesos o dinámicas identificadas. Ahora bien, no todo el diagnóstico político se refiere a procesos globales por más que se incluyan sus manifestaciones locales. Existe un proceso en cierta medida autónomo, por lo menos en cuanto a los sujetos de ese proceso. Entre 1979 y 1992 habría ocurrido un proceso de cambio político. Lo que suele llamarse transición política. Ésta habría finalizado, entre 1992 y 1994, con la instauración de un nuevo régimen político que tiene como fundamentos los Acuerdos de Paz firmados entre las cúpulas del Frente Farabundo Martí para la Liberación Nacional (FMLN) y del gobierno, controlado por el partido Alianza Republicana Nacionalista (ARENA) ${ }^{5}$. El contexto internacional de fin de la Guerra Fría, con la caída del bloque socialista y el consiguiente triunfo geopolítico del capitalismo, habría facilitado el final de un transición política prolongada cuyo 
punto culminante estaría en las llamadas "elecciones del siglo", de 1994. Las características del régimen que se instaura son el resultado del juego de las fuerzas en contienda. Por esta razón hablo de un proceso local.

\section{Cuadro 1 \\ Dinámicas globales y locales del diagnóstico político}

\begin{tabular}{c|c}
\hline Dinámica global & Dinámica local \\
\hline CRISIS DEL ESTADO NACIONAL & INTERNACIONALIZACIÓN DE LA \\
POLITICA NACIONAL
\end{tabular}

$\checkmark$ Fin de la Guerra Fría

- Globalización capitalista

Ascenso de la cultura iconocrática

Crisis de la representación política

Incremento de las migraciones por razones económicas y el flujo cultural que ellas provocan

Revolución tecnológica y la Nueva División Internacional del trabajo

Cambio climático y deterioro del medio ambiente
Pérdida de identidad de los actores colectivos

Reestructuración del aparato estatal

Personalización de la política

Crisis de los partidos políticos y de las viejas formas de representación de intereses

Hegemonía de los Estados Unidos

Mayor protagonismo de las relaciones internacionales

Amenaza a la sobrevivencia de la comunidad política

Fuente: Elaboración propia.

Ahora bien, la importancia de este proceso local reside en que allí se han establecido las reglas del juego para la toma de decisiones que afectan a la comunidad política nacional y que en la mayoría de los casos dichas decisiones vienen condicionadas por las dinámicas globales. Por de pronto, me interesa enfatizar que nada garantizaba que el proceso de cambio político desembocaría en una democracia. En términos teóricos, un proceso de transición nos lleva de un régimen a otro, sin importar el tipo de régimen, ni de salida ni de llegada. Desde este punto de vista teórico, bien podríamos accptar que la transición se llevó a cabo desde un régimen autoritario mas el punto de llegada no estaría nada claro, excepto que los protagonistas del diseño institucional adoptado serían las cúpulas de los actores colectivos contendientes. Tarea ingente es determinar el tipo de régimen político en el que vivimos para facilitar la comprensión del proceso interno. Siguiendo la teoría de los procesos de transición, podríamos afirmar que vivimos una etapa 
de consolidación del nuevo régimen. Nada garantiza que la consolidación llegue a darse. Up proceso de involución o regresión es probable. E, incluso, podría presentarse una situación de persistencia con inestabilidad. No es aquí el momento de discutir todas estas posibilidades. Me interesa ante toda que las y los lectores no identifiquen automálicamente al nuevo régimen como una democracia. No conozco un trabajo donde se haya realizado este análisis para El Salvador. Lo que normalmente uno encuentra es la asunción de que vivimos en una democracia, aunque sca adjetivada (delegativa, de baja intensidad, electorera, no consolidada, elc.).

Aunque no sea objelivo mío llevar a cabo aquí el análisis del tipo de régimen político salvadoreño, me parece importante destacar el protagonismo que en éstc lienen las ćlites. Con este propósito considero de utilidad un esquema analílico que propuso R. Dahl en 197 I en su libro Le peliarquía. Tomando en cuenta dos dimensiones (participación y debate público), Dahl sugirió que las poliarquías cran el lipo de regímenes que más se parecían al ideal de la democracia. Desde csile punto de vista, las democracias realmente existentes serían poliarquías. No el gohierno del demos sino el gobierno de muchos. Lo que tendríamos en la rcalidad scrían regímenes más o menos democráticos. Lo democrático sería un asunto de grado a partir de la existencia de un mínimo de condiciones que lo harían posible. Pues bien, al seleccionar la participación y el debate público de cntre ese mínimo de condiciones, Dahl establece tres categorías (como tipos ideales wcherianos) alternativas a la poliarquía. En primer lugar, si hay poca participación y poco debate público estaríamos ante una hegemonía cerrada. Si se incrementa la participación pero no el debate público nos estaríamos desplazando hacia la zona de las hegemonías representativas. Ahora bien, si se tiene mucho debate público, pero poca participación, estaríamos más bien en la zona de las oligarquías competitivas (ver ligura 1). Si nos olvidamos de la asociación que en el país se suele hacer cntre oligarquía y grandes terratenientes, y pensamos más bien en términos de pocos como en oligopolio, un régimen político de oligarquía competitiva estaría haciendo referencia a un régimen donde predominan pocos y csos pocos se disputan, incluso en elecciones, el poder político.

\section{Figura 1}

Tipología de Regímenes políticos, SEgún PaRTicipación v debate Público

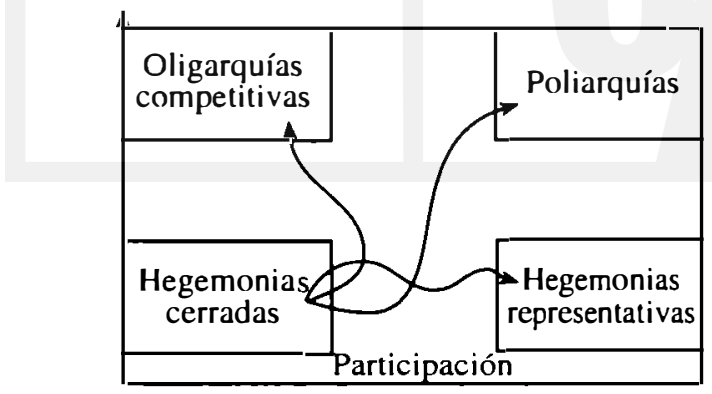


En la figura 2 he tratado de presentar de una forma visual más adecuada la misma información del cuadro 1, incluyendo ahora lo que sería la dinámica propiamente local que caracteriza primordialmente el proceso político salvadoreño. Las puntas de flecha no indican causalidad. Se refieren más bien a la influencia que las dinámicas globales, con sus manifestaciones locales, llevan a cabo sobre el proceso político nacional. Esta figura admite la siguiente lectura. En términos políticos, es decir, en tanto gestión del conflicto social mediante la adopción e implementación de decisiones vinculantes, la comunidad política salvadoreña se ve sometida a una serie de dinámicas globales sobre las que poco control tiene y sin embargo, con las que tiene que habérselas. Las decisiones adoptadas y luego implementadas, así como la forma de su adopción e implementación, dependen en parte de quienes participan en el proceso de toma de decisiones. El régimen político instaurado a partir de los Acuerdos de Paz ha vuelto protagonistas de este proceso de toma de decisiones a las cúpulas de las principales fuerzas políticas, nacionales o internacionales ${ }^{\dagger}$. El demos no parece tener mayor participación y en no pocos casos ha mostrado inconformidad con las decisiones adoptadas. Otro problema es si esa inconformidad haya sido o no políticamente eficaz.

Como resultado de este protagonismo elitista y marginación del demos, habría que preguntarse sobre lo adecuado o no al referirse a una supuesta erosión de las instituciones creadas por los Acuerdos de Paz. Bien podría tratarse del proceso normal de consolidación de unas instituciones que solamente serían efectivas cuando estuviesen amenazados los derechos conquistados por las élites. Una lectura en el scntido de crosión o involución institucional podría pecar de ingenuidad al creer que realmente una democracia podía ser instaurada y consolidarse por default como parccía ser el caso salvadoreño. La reciente historia política salvadoreña no estaba caracterizada precisamente por una lucha por la democracia. Los objetivos de las principales fucrzas en contienda eran otros. La instauración de un régimen socialista, por un lado; la aniquilación de quienes lo intentaban, por otro. Como lo señalé anteriormente, es cl contexto de fin de la guerra fría y el real balance de fuerzas al interior del país el que termina poniendo los límites para las aspiraciones y posterior acción de los principales actores políiticos. Aunque éstos adoptaron el discurso democrático, su práctica siguió por los canales autoritarios a los que estaban acostumbrados ${ }^{k}$. La apatía política, el descrédito hacia los políticos y hacia las cstructuras de intermediación viene a ser así la consecuencia lógica e histórica de una forma de interpretación del proceso político por parte del demos. Es como un tomar conciencia de los intereses de quiénes son los que prevalecen en la negociación política. Si a esto se le llama desencanto no habría que preocuparse. Es mejor cstar des-encantados que estar bajo el hechizo, bajo la ilusión, bajo un encanto. Una vez des-encantado, tal vez el demos esté mejor preparado para iniciar el largo camino de la democratización. Por supuesto, también puede huir de este reto. Más adelante volveré sobre este punto. A continuación explicaré un poco cada una de las dinámicas señaladas en la figura 2 . 


\subsection{Crisis del Estado Nacional e internacionalización de la política nacional}

El pepsamiento político tradicional ha considerado como elementos constitutivos del Estado: un territorio, una comunidad política y la autonomía para tomar decisiones vinculantes para esa comunidad en ese territorio (la soberanía). Pues bien, estos tres elementos son puestos en cuestión por las dinámicas globalizantes. En cuanto al primero, demarcado por el trazado de fronteras como un ámbito físico —que incluye tierra, agua, espacio aéreo y subsuelo- en donde rigen las decisiones vinculantes, su importancia se está viendo modificada. En la actualidad, las fronteras territoriales no garantizan la seguridad militar ni la capacidad económica de los Estados más desarrollados. No se diga entonces de la vulnerabilidad a la que se ven sometidos Estados como los centroamericanos. Particularmente, en el caso salvadoreño, las fronteras territoriales pueden estarse convirtiendo en una amenaza para la sobrevivencia de la comunidad política. Los recursos naturales con los que cuenta el país amenazan el futuro de las nuevas generaciones. Además, existen procesos transfronterizos que burlan todo tipo de control estatal como el tráfico de migrantes y estupefacientes, así como el contrabando de mercancías nuevas o usadas. La internacionalización de la actividad linanciera y económica cada vez más ignoran las fronteras territoriales.

En cuanto a la población o comunidad política, puede decirse que cada vez más estamos enfrentados a la pregunta sobre quiénes forman parte activa de ella. ¿Quiénes son los sujetos de los derechos y deberes políticos? ¿Quiénes son los que activamente participan de los procesos de toma de decisiones vinculantes? ¿Los nacionales? ¿Los que, aún no siendo nacionales, residen permanentemente en el territorio nacional? ¿O los que, no siendo nacionales, residen esporádicamente en el país pero que tienen negocios económicos o políticos lo suficientemente importantes como para querer influir en la toma de decisiones? ¿Qué puede decirse de los migrantes? ¿Tienen derechos? Podría formular más pregunlas y nos daríamos cuenta que no todo está claro en relación a quiénes constituyen hoy la comunidad política de los Estados.

Otra mancra de enfocar las relaciones entre Estado nacional y población es a través del sentimiento de pertenencia de los ciudadanos al territorio. Pues bien, lo que se dice actualmente es que ese sentimiento sufre un proceso de erosión. "En la cra de redes, la relación de los ciudadanos con el cuerpo político entra en competencia con la infinidad de conexiones que establecen fuera de él, de suerte que la política, lejos de ser un principio organizador de la vida de los hombres en socicdad, aparece como una actividad secundaria, como una construcción artificial incluso, inadaptada para la solución de los problemas prácticos del mundo contemporánco" (Guéhenno, 1995:35). Además, la facilidad creciente para comunicarse y desplazarse entre diferentes territorios hace surgir un sentimiento de pertenencia ya no sólo a un Estado sino a varios Estados. Todo depende de los ticmpos de estancia, redes de amistad, negocios o familiares que se haya logrado establecer. ¿A qué otra cosa aluden si no los ciudadanos del mundo? 
Figura 2

Diagnóstico político

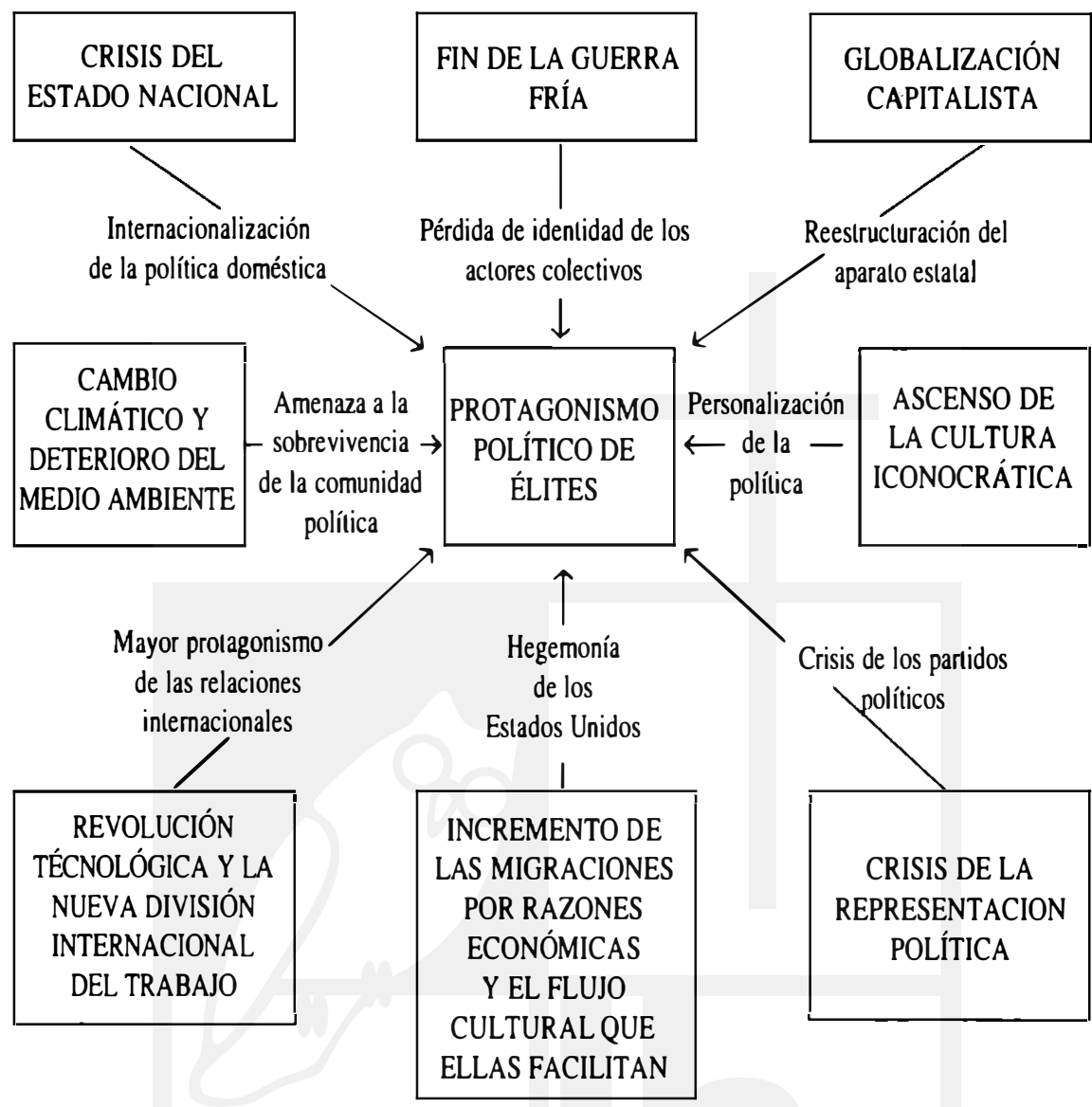

En los debates legales y en las polémicas políticas abundan las referencias a la soberanía. Incluso llegó a utilizarse el tema de la soberanía para definir tipologías estatales. Así, por ejemplo, se llegó a hablar de estados centrales y periféricos, igualmente se habló de estados dependientes para identificar los estados cuyas decisiones vinculantes estaban en función del desarrollo de otros estados. Actualmente cada vez se habla más de estados interdependientes lo cual, desde mi punto de vista, no sería nada nuevo ni tendría por qué ser problemático. Tal vez reconocer que algunos estados pierden soberanía asuste cuando se trata de estados que durante muchos años fueron soberanos en gran medida. En el contexto de procesos de integración regional es comprensible que algunos estados europeos "tiemblen" ante el traspaso de competencias a instituciones suprana- 
cionales. Pero no es esta la situación en el contexto de estados tradicionalmente dependientes como El Salvador.

Este Cuestionamiento de los tres elementos constitutivos del Estado nos conduce a reconocer la internacionalización de la política doméstica. Es necesario reconocer, si todavía no se ha hecho, la mayor importancia de actores extranjeros en los procesos de toma de decisiones políticas internas. Estos actores no son sólo políticos sino también y sobre todo económicos. Puede sonar a falta de patriotismo, pero considero que este proceso no necesariamente tiene consecuencias negativas. Aquí, como en muchas otras cosas, todo depende qué es lo que se persigue.

\subsection{Fin de la Guerra Fría y pérdida de identidad de los actores colectivos}

Al referime a los actores colectivos, trato de aquellos cuya identidad fue forjada durante el siglo XX en el contexto del enfrentamiento Este-Oeste, socialismo-capitalismo. Éste fue uno de los clivajes sobre los cuales se definieron dos identidades colectivas muy fuertes en el país y que explican en buena medida la polarización política heredada del régimen autoritario que defendía posiciones pro-capitalistas. Los principales actores políticos surgidos de este clivaje, y que actualmente son los dos partidos mayoritarios del país, son ARENA y el FMLN". Políticamente, las posiciones de estos dos partidos se traducían claramente en planteamientos conservadores y revolucionarios. En ARENA, el anticomunismo venía a ser como el elemento vital para consolidar posiciones frente al FMLN cuando éste era frente guerrillero y todavía antes de su constitución. De hecho, el anticomunismo facilita la articulación e integración de diversos sectores empresariales, de clase media y grupos de campesinos para dar su apoyo a los sectores más duros de las fuerzas armadas en su lucha contra lo que ellos llamaban, en los años setenta y ochenta, la subversión comunista.

Por otro lado, ante la percepción generalizada de que en El Salvador de los años sctenta era imposible impulsar reformas, tanto políticas como económicas, que permitieran una vida digna de seres humanos a la inmensa mayoría pobre de salvadoreños, grupos opositores al régimen militar se fueron radicalizando hasta adoptar posiciones revolucionarias de corte marxista. A un clivaje de tipo pro y antirégimen (que hasta entonces había servido de base para la constitución de identidades políticas traducidas en términos de gobierno-oposición y del cual provienen los partidos de Conciliación Nacional, PCN, y Demócrata Cristiano, PDC) sc añadió el clivaje pro y antisistema. La definición como antirégimen y antisistema de los grupos que en 1981 conformaron el FMLN les proporcionó cl sustento identitario ${ }^{10}$. No niego la existencia de planteamientos propositivos en los primeros años de existencia del FMLN. Allí están las propuestas sobre un gobierno democrático y revolucionario o sobre un gobierno de amplia participación, que, además, eran la manifestación del deslizamiento gradual hacia posiciones, por lo 
menos, sistémicas. Doce años después de su constitución, las posiciones antisistémicas del FMLN habían perdido fuerza para dar paso a posiciones sistémicas y facilitar la negociación, dentro del sistema, de un nuevo régimen político.

El realismo político y un contexto internacional en ligero cambio con el dcrumbe del bloque socialista propició la negociación de Acuerdos de Paz entre un gobierno, controlado por el partido ARENA, y el FMLN. Podría extenderme aquí en el análisis del cálculo político que llevaron a cabo ambos actores en ese momento para adoptar las mejores posiciones para continuar el enfrentamiento aunque ahora en la arena formal de la política. Sin embargo, aquí estoy más interesado en el impacto que el cambio político del escenario mundial tiene en las identidades forjadas en el escenario nacional. En este sentido, la desaparición del bloque socialista mina el elemento aglutinador e identitario principal. Por un lado, ARENA sc ve enfrentada al problema de tener una identidad anticomunista en un contexto donde el comunismo internacional ha dejado de ser problema para el capitalismo. Ahora el comunismo frente al que ARENA dice que hay que delicnderse puede ser más un fantasma. Y allí está el problema, apelar a la amenaza de un fantasma para aglutinar a sus bases militantes y simpatizantes cuando cada vez es más difícil ocultar los problemas reales que está provocando cl desarrollo actual del capitalismo.

Por el lado del FMLN sucede algo análogo. Ahora tiene que aceptar el trago amargo de jugar con las reglas del capitalismo". Y cso le genera problemas de identidad y de falta de claridad sobre su proyecto. Se trata de una situación nada fácil de manejar para el liderazgo del Frente. Abandonar las posturas anticapitalistas puede tener sus costos políticos al interior del partido, pues es como abandonar su propia identidad. Pero mantenerlas en el nuevo contexto mundial también puede tener sus costos políticos para poder avanzar y convertirse en la luerza política mayoritaria del país. Como veremos más adclante, hay otros lactores que van contra las posturas anticapitalistas. Para mencionar nada más uno: ¿Quć decir de los más de dos millones de salvadoreños que viven luera del país, en contextos capitalistas y que mantienen fucrtes vínculos lamiliarcs? Pcro, por favor, que no se me entienda mal. No estoy apostando por el capitalismo y mucho menos en su versión neoliberal. Estas rellexiones apuntan más bien al problema de basar un identidad colectiva en una postura anticapitalista en un contexto global de hegemonía capitalista. Para las aspiraciones de gobierno del Frente este es un dato ineludible.

\subsection{Globalización capitalista y reestructuración del aparato estatal}

La ruptura del equilibrio entre el desarrollo de las fuerzas productivas y las relaciones sociales de producción propiciado por la revolución en las tecnologías de la información ha permitido el paso a un nivel superior de desarrollo del capitalismo. Creo que éste es el proceso que subyace a la reestructuración del aparato estatal que se registra en todas aquellas partes del mundo que van siendo 
incorporadas al proceso de globalización del capital. Un proceso que se materializa en las llamadas privatizaciones. Dos cosas quiero decir al respecto.

Por In lado, en la medida en que las privatizaciones de las empresas estatales favorecen una nueva acumulación de capital, aquéllas no son procesos neutros. De ellas salen potenciados determinados individuos o grupos que frecuentemente ya tienen acumulado cierto poder económico y que ahora buscan un mayor poder de influencia en la toma de decisiones vinculantes. En un diagnóslico como el que estoy dibujando, creo que es fundamental identificar a estos individuos o grupos, pues ellos tienen la sartén por el mango. Sin embargo, no es este el momento ni el lugar para realizar esta tarea. Aquí me basta con señalar que, con las privatizaciones, nuevos actores han hecho su aparición en la arena política. Es el caso, por ejemplo, de los mayores accionistas de las empresas telefónicas, de distribución de la energía eléctrica y de las administradoras de pensiones. Por supuesto, a éstos habría que agregar los mayores accionistas de los bancos. Es indudable que estos individuos y grupos tienen intereses económicos suficientes, como para querer influir en aquellas decisiones colectivas que puedan afectar dichos intereses.

Por otro lado, las privatizaciones implican la redefinición de los ámbitos de acción de las iniciativas privadas y estatales. Las primeras fueron asociadas al mercado y las segundas fueron asociadas a un ámbito público ${ }^{12}$. La redefinición de esos ámbitos se traduce en una disminución del ámbito estatal a favor del ámbito privado. Desde una perspectiva liberal, este proceso podría ser alabado. De hecho es lo que buscan los neoliberales, reducir el ámbito de acción del Estado al mínimo ${ }^{13}$. En este proceso, los gobiernos terminan siendo rehenes de los grupos que impulsan las privatizaciones. Pero también ocurre que al culpar al Estado de todos los males se fomenta el desinterés y apatía por la política entre la ciudadanía. Y ésta es otra forma de favorecer las privatizaciones. Se ganan las mentes y los corazones a su favor. La reestructuración del aparato estatal llega incluso a la redefinición de espacios públicos que ahora se tornan privados. ¡¿Qué más pueden ser las plazas comerciales con vigilancia privada?! Son los nuevos mercados públicos, incluso utilizados como lugares de recreación y encuentro (como las plazas y parques públicos) pero en propiedades privadas, con seguridad y vigilancia privada. Así, poco a poco, y desde distintos escenarios, lo estatal sigue perdiendo terreno. Y, como veremos más adelante, a cllo contribuyen los medios de comunicación de masas. Por todos lados, hay acusaciones contra los políticos, la política, el Estado, etc. ¡ Y hay un silencio tremendo respecto de los fallos del mercado y de los vicios privados!

\subsection{Ascenso de la cultura iconocrática y personalización de la política}

Con la llegada de la televisión, la cultura de masas está más proclive a las emociones antes que a las argumentaciones, como podía estarlo a través de los periódicos o prensa escrita. La televisión ha impuesto una cultura. El culto a la 
imagen, donde la apariencia se impone sobre otras caraclerísticas de lo real. Incluso se ha dicho que aquello que no pasa por la pantalla del televisor no tiene existencia. Esta afirmación puede parecer extravagante. Pero no podemos negar el influjo que ejerce la televisión a la hora de hacernos una imagen de lo que pasa en el mundo. Gracias a las imágenes televisadas de una desgracia como Tos pasados terremotos de enero y febrero en El Salvador, muchísima gente en diversos lugares del mundo se movilizaron para ayudar a las víctimas. Cuanto más desgarradoras las imágenes, mayor fue el impacto movilizador. De igual manera, gracias a las imágenes televisadas de las movilizaciones en Seattle, Washington, Davos, Génova, etc., podemos darnos cuenta de la existencia de un movimiento antiglobalización en los llamados países desarrollados.

La preponderancia de la imagen supone un ascenso de la televisión como actor político. Con el favor de la imagen como evidencia la televisión tiene un inmenso poder de influencia en los procesos políticos. Comparte el poder de establecer la agenda con la prensa escrita pero cuenta con la ventaja de su cuasiubicuidad y velocidad en la producción de noticias, además del mayor público que está expuesto a su mensaje. Como todo medio de comunicación la televisión ticne sus reglas de producción a las que los actores tienen que someterse. La presencia física es sumamente importante. Basta ver cómo hay salones de belleza o boutiques involucradas en los programas noticieros con la responsabilidad de lograr la mejor apariencia de los presentadores. Esto es clarísimo en los programas de opinión. ¡Ay de aquel presentador con mala presentación!

La intervención de la televisión en programas de contenido político ha tenido su impacto sobre la forma de hacer política. No sólo porque logra imponer su formato a los protagonistas de la noticia política. Sino sobre todo porque disputa el rol de mediador a otros agentes de intermediación. Aquí me interesa enfatizar la disputa mediática entre televisión y partidos. Ambos actores median entre el sistema de instituciones políticas y la comunidad política. Pero mientras los partidos cada vez están más desprestigiados ante los ojos de la opinión pública, los medios (entre ellos la televisión) gozan de mayor prestigio. El cuadro 2 muestra información proveniente de encuestas de opinión realizadas por el Instituto Universitario de Opinión Pública (IUDOP) de la UCA, entre 1995 y 2000 , que permite comparar los niveles de confianza entre medios de comunicación (cntre cllos, la tclevisión) y los partidos políticos. El índice de confianza siempre ha sido mayor para los primeros.

Para gozar de estos mayores niveles de confianza, la televisión cuenta por supuesto con la ayuda de la imagen. Es su evidencia. ¿Quién podría dudar de lo que estamos viendo con nuestros propios ojos? Desde este punto de vista los partidos salen mal parados pues no es infrecuente que lo que ven nuestros ojos es lo contrario de lo que los partidos y sus candidatos o voceros sostienen. Ahora bien, el resultado de esta lucha mediática a favor de los medios de comu- 
nicación de masas (especialmente la televisión) tiene su impacto político. Propicia una mayor personalización de la política. Pone en contacto directo a los políticos y la fomunidad. Pareciera tratarse de una relación no mediada. Incluso puede hablarse directamente, en tiempo real, con los políticos desde la comodidad que nos proporciona nuestra propia casa. Basta una llamada por teléfono al canal de televisión donde está presentándose el político y habremos entrado en contacto con él o ella. Para hacerle llegar nuestros pareceres no necesitamos del partido. Ahora lo podemos hacer directamente gracias a los medios. Pero, ¡cuidado! Este directamente está mediado. Es el medio televisión el que media. No podemos llegar a cualquier político sino a aquel o aquella a quien el medio invita a su programa. También es usual que la agenda sobre la cual podemos interrogar al político o política invitada sea puesta por el medio. Igualmente, el tiempo de interpelación lo tenemos contado. Nos lo impone el medio.

\section{Cuadro 2}

ÍNDICE DE CONFIANZA EN LOS MEDIOS DE COMUNICACIÓN SALVADOREÑOS Y I.OS PARTIDOS POLÍTICOS

\begin{tabular}{l|ccccccc}
\hline \multirow{2}{*}{ Institución } & \multicolumn{7}{|c}{ Índice de confianza } \\
\cline { 2 - 8 } & Feb/95 & $\mathrm{Ag} / 96$ & $\mathrm{Jul} / 97$ & May/98 & May/99 & SepU99 & Dic/00 \\
\hline MEDIOS DE COMUNICACIÓN & 2.78 & $2.53 \mathrm{~B}$ & 2.96 & 2.89 & 2.93 & $2.5 \mathrm{C}$ & 2.71 \\
PARTIDOS POLITICOS & 1.62 & n.d. & 1.65 & 1.76 & 1.80 & 1.67 & 1.68 \\
\hline
\end{tabular}

NOTAS:

12.d.: no disponible.

a: Se construyó según una escala de 1 a 4, donde 1 es ninguna o nada de confianza y 4 es mucha confianza.

b: Calculado como promedio de los niveles de confianza para prensa escrita, noticias de radio y noticias de televisión discriminadas por el IUDOP.

c: Calculado como promedio de los niveles de confianza para prensa escrita y televisión.

Fuente: elaboración propia sobre datos de las encuestas del IUDOP \#46, 57, 64, 69 , 76.80 y 86 .

La personalización de la política es pues un proceso que camina de la mano con el predominio de la televisión y de la imagen televisada. Puede llegarse al absurdo de hacer depender la gestión pública no tanto de las capacidades de un equipo de gobierno (nacional o local) sino de la imagen que los gobernantes proyectan y de cómo dicen lo que dicen a través de las cámaras ${ }^{14}$. La gramática de la imagen ha terminado cooptando el quehacer político. Importa ahora más la persona que comunica y ésta a través de la imagen que proyecta. Por eso he hablado de iconocracia y de personalización de la política. Pero no se trata de una personalización que elimina cualquier mediación. Al contrario, es una personalización mediática en cuanto está mediada por un medio de comunicación masiva. 


\subsection{Crisis de la representación política y crisis de los partidos políticos}

Vinculada con el ascenso de la televisión como mediador político, se encuentra lo que ha dado en denominarse crisis de la representación política, en general, y crisis de los partidos políticos, en particular. Los ciudadanos no sá sienten representados en las instituciones políticas y ven a los partidos (y demás organizaciones intermedias) como "centro de operaciones de la polílica corrupta" (Porras Nadales, 1996:119). En cierta medida los crecientes niveles de ausentismó que se registran en países curopeos y latinoamericanos liene que ver con este alcjamiento entre partidos y ciudadanos. Los primeros parecen estar más ocupados en los intereses partidistas que en los de los ciudadanos.

Ahora bien, algunos analistas prelieren no hablar de crisis de los partidos, incluso allí donde éstos son muy débiles dado el nivel de desarrollo político en el que se mueven. Es el caso de Rovira Mas (1994), quien, analizando los partidos políticos centroamericanos, preliere hablar de malestar con los partidos. Éste sc manilestaría en diversas áreas:

- Corrupción de políticos o luncionarios gubernamentales prominentes.

- Apcrtura insuficiente de los partidos a la ciudadanía.

- Modernización incompleta.

- Falta de democratización interna.

- Limitada representatividad de los diversos interes sociales.

- Obstaculización de la emergencia de nuevos contendientes.

- Incficacia del sistema político en términos de políticas públicas y del sistema de partidos como inadecuado sistema de canalización política de la sociedad.

Que este malestar es gencralizado puede constatarse al verlo manilestarse aún en democracias consolidadas como la costarricense. Refiriéndose a los partidos políticos de Costa Rica, Cerdas (1995) sostenía que la credibilidad en ellos "decrece en proporción directa al canibalismo interno que caracteriza las precampañas; y las campañas propiamente dichas. Predominan así la virulencia de la conlirontación que se produce entre quienes disputan los puestos de clección popular; y los escándalos constantes de corrupción en el mancjo de los asuntos públicos, que afectan por igual a miembros de las principales formaciones políticas”. Cicrto es que estas afirmaciones están dichas hace algunos años pero cualquier observador de los partidos políticos no dudará en aceptar su vigencia incluso en realidades políticas distintas a la costarricense.

Para el caso salvadoreño, las cosas no parecen ser muy distintas aunque hay que tomar en consideración las especificidades. Históricamente ha sido imposible consolidar un sistema de partidos en el país. Aunque puede registrarse la 
existencia de partidos políticos desde finales del siglo XIX, un contexto compelitivo para el desarrollo de los partidos únicamente puede fecharse para la década de 1990. Una característica de la vida partidista nacional fue el recurrente aparecer y desaparecer partidos, no solo pequeños sino incluso grandes partidos. No solo partidos en la oposición, sino también en el gobierno. Este constante crear y destruir partidos en el periodo autoritario marca el desarrollo actual de los mismos. Las disputas que amenazan la cohesión interna de los partidos actuales aparecen ante los ojos de los ciudadanos como disputas personales y no tanto como desafíos para su desarrollo institucional. De allí que los retos del desarrollo político partidista son interpretados como crisis de los partidos.

\subsection{Incremento de las migraciones por razones económicas y el flujo cultu- ral que ellas provocan. Hegemonía de los Estados Unidos}

Uno de los procesos globales que se está volviendo inmanejable para muchos gobiernos es el de las migraciones transnacionales. De África y Asia hacia Europa occidental, así como de algunos países asiáticos hacia otros países asiáticos, y de América Latina hacia Estados Unidos, miles de personas salen en busca de nuevos horizontes y posibilidades para subsistir ellos y sus familias. En algunos lugares, estas migraciones tienen motivaciones políticas, pero aquí, y por lo que a El Salvador se refiere, interesan las migraciones con motivaciones cconómicas, porque son éstas las asociadas con la globalización económica.

A finales de la década de 1970, comienza a registrarse en El Salvador un éxodo de personas, individualmente o en grupos, hacia otros países de la región centroamericana y posteriormentc, ya en la década de 1980, hacia México, los Estados Unidos, Canadá, Australia y Suecia, principalmente. Este éxodo se conslituyc inicialmentc por refugiados, asilados, exiliados, por motivaciones políticas. En la medida en que el éxodo es masivo e intervienen entidades como lá Organización Internacional de las Migraciones (OIM) varios miles de salvadoreños aprovechan csta coyuntura para salir en busca de oportunidades económicas en los países que ofrecen programas de inmigración para grupos familiares. Es importante enlatizar en la racionalidad familiar que subyace a este flujo de emigrantes (juc luego constituirían las colonias de salvadoreños en el extranjero (Canadá, Australia y Succia) en la inedida en que dichos programas estaban dirigidos a grupos familiares jóvenes. En no pocos casos con hijos e hijas pequeñas.

El otro llujo, probablemente sobre el que más se ha hablado, es el de los que sc lucron, legal o ilegalmente hacia los Estados Unidos y que hoy constituyen un cuarto de la población salvadoreña. También aquí operó una racionalidad individual-lamiliar a la hora de tomar la decisión. Es cierto que ya en los Estaclos Unidos se desarrollaron redes y asociaciones de migrantes provenientes de un mismo punto de partida en El Salvador y que luego serían capaces de inlluir en la mejora de las condiciones de vida de sus pueblos. Sin embargo, lo que quicro enfatizar es que acjucllas decisiones individuales-familiares de abandonar 
el país tendrían con el tiempo un efecto social. Serían factor de cambio. En términos sociológicos estamos aquí ante el fenómeno de las consecuencias no deseadas de la acción. Y aquí me refiero no sólo al tema de la cantidad de divisas que llegan al país en términos de ayuda familiar en remesas sino al influjo cultural que, por la vía de las relaciones entre familiares aquí y allá, se establece entre los países de origen y llegada. Por supuesto, que este influjo no es simétrico. La carga cultural que llega desde los Estados Unidos hacia El Salvador no es equivalente a la que puede registrarse en la dirección contraria. El american way of life ha encontrado canales de difusión a través de las relaciones familiares, ya sea porque con la ayuda económica las familias aquí en el país han accedido a productos de consumo de la cultura estadounidense, ya sea porque migrantes y sus familias han experimentado en carne propia un proceso de resocialización'

En términos de un diagnóstico pensado para la definición de ejes de acción creo que es clave tomar en cuenta que este flujo cultural se traduce en hegemonía política. En la medida en que ese flujo cultural se da predominantemente desde los Estados Unidos, la hegemonía es estadounidense. Cuando se pretende influir en las estructuras sociales para hacer que éstas posibiliten una vida digna para lo que la Misión de la UCA llama "mayorías" y se busca promover unas relaciones sociales justas no debe pasarse por alto este dato. Parafraseando a Sobrino (1999), habría que decir que, para ser honestos con la realidad, no hay que ignorar que cerca de un cuarto de la población salvadoreña vive en y de los Estados Unidos y otro tanto más desea emigrar hacia allí. Que la sociedad estadounidense es el modelo de sociedad que buena parte de la población salvadoreña anhela. Que es muy probable que esta población reconozca los males y delectos de aquel país, pcro que aún así lo consideran mejor (para su futuro) que el nuestro. Y, por tanto, que prefieren el orden social estadounidense (o algo así) antes que el des-orden social salvadoreño ${ }^{16}$.

Hay muchas cosas más que pueden decirse sobre la dinámica migratoria hacia luera. Pero deseo agregar unas líneas sobre dos tipos de flujos migratorios que también afectan la convivencia de los nacionales salvadoreños en su territorio $^{17}$. Por un lado, habría que indagar sobre los efectos que podría estar causando la presencia creciente de hondureños y nicaragüenses en territorio salvadoreño. Como consecuencia no deseada de la Ley de Integración Monetaria o dolarización, hondureños y nicaragüenses se ven atraídos hacia El Salvador por la probabilidad de encontrar un trabajo remunerado en dólares. Ya no necesitarían viajar ilegalmente hasta los Estados Unidos sino a este su vecino país y realizar allí una especie de sueño salvadoreño. Como resultado, compiten por puestos de trabajo, por muy mal pagados que sean, con salvadoreños. Por otro lado, El Salvador parece ser parte de la ruta de migrantes latinoamericanos y asiáticos hacia los Estados Unidos. Frecuentemente son detectados en diversos puntos del territorio salvadoreño grupos de migrantes en esa dirección. Estos migrantes están de paso y no plantean competencia por puestos de trabajo. Pero sí plantean un problema 
de doble moral en la política migratoria salvadoreña. Las autoridades gubernamentales reclaman un trato para los migrantes salvadoreños en México y Estados Unidos que no están dispuestos a dar a los extranjeros ilegales que son sorprendidos en el territorio salvadoreño.

\subsection{Revolución tecnológica y la nueva división internacional del trabajo. Mayor protagonismo de las relaciones internacionales}

Desde la década de 1960, el planeta vive bajo los efectos de una nueva revolución tecnológica cuyo centro está, por supuesto, en los países industrializados del Norte. Como se sabe esta revolución se da en las llamadas tecnologías de la información (microelectrónica, informática, telecomunicaciones, televisión, radio, optoelectrónica e ingeniería genética). Caracteriza a esta revolución la aplicación de conocimiento e información a aparatos de generación de conocimiento y procesamiento de la información/comunicación, en un círculo de retroalimentación acumulativo entre la innovación y sus usos (Castells, 1999:58). El Salvador, aunque no es productor, pero sí consumidor de esta tecnología, ha sido integrado (aunque sea fragmentariamente, desde el punto de vista de quienes tienen acceso a dicha tecnología) al ámbito de esta revolución y es posible comenzar a percibir algunos de sus efectos. Uno de los más importantes tiene que ver con la menor importancia que tienen ahora los productos tradicionales salvadoreños de exportación (sobre todo el café) mediante los cuales el país estaba integrado a las redes de comercio mundial. Este proceso pone en cuestión la agroexportación como actividad productiva de inserción en el mercado capitalista global.

También se ha reconocido que el auge de las nuevas tecnologías ha producido un cambio en la estruclura productiva de los países desarrollados. Algunos hablan del surgimiento del posindustrialismo en dichos países y es posible identificar un auge del sector servicios allí así como el traslado de la industria contaminante hacia otras zonas del planeta, en el llamado Sur. Pero también las nuevas tecnologías han posibilitado deslocalizar la cadena de producción de muchas mercancías integrando diversas zonas geográficas en un mismo proceso productivo, dependiendo de las llamadas ventajas comparativas que ofrecen los diversos países a la acumulación capitalista.

Los cambios operados a nivel de la producción mundial de mercancías sc traducen en una nueva división internacional del trabajo. Y es ésta la que sustenta el auge de las relaciones internacionales como ámbito de acción de los cstados y empresas transnacionales. No sólo se trata de integrarse de la mejor manera al proceso productivo y de circulación de mercancías a nivel mundial. Aquí se están afectando condiciones de trabajo (la llamada flexibilización laboral) que son impuestas o negociadas (según sea el caso) entre actores internacionales. Estos cambios también impulsan los procesos migratorios de raíz económica a los que me refería en párrafos anteriores. Lo cual hace que los gobiernos nacionales tengan que pactar determinadas condiciones laborales para posibilitar in- 
versiones productivas. En algunos casos, la relación no se da entre gobiernos sino entre agencias financieras y gobiemos. En otros casos, las negociaciones son entre empresas transnacionales y gobiernos. Este último caso explica en parte que algunos gobiernos (como los centroamericanos) promuevan agencias o ellos mismos salgan en busca de inversores extranjeros.

Lo que para el caso salvadoreño me interesa resaltar en este diagnóstico es la mayor importancia que adquiere la política internacional. Junto a la globalización, hay procesos de regionalización. En ambos escenarios, los gobiernos juegan un papel importante a través de los tratados internacionales bilaterales o multilaterales. La búsqueda de inversores extranjeros para paliar las debilidades de los productores locales en la generación de empleo también ha sido asumida por los gobiernos nacionales. Los procesos migratorios que acompañan la re-estructuración capitalista suelen generar conflictos fronterizos que se intentan resolver por la vía diplomática. En fin, muchas de las decisiones que afectan a la comunidad política local son tomadas en escenarios internacionales y uno de los principales actores en esos escenarios ha de ser indudablemente (aunque no exclusivamente) el gobierno y su red de funcionarios en el extranjero.

\subsection{Cambio climático y deterioro del medio ambiente. Amenaza a la sobre- vivencia de la comunidad política}

Probablemente son pocos lectores los que nunca han escuchado hablar sobre el cambio climático y el deterioro del medio ambiente a nivel mundial. Pocos, tal vez, sean también los que están bien informados al respecto. Sin embargo, la sequía por la que atraviesa Centroamérica este año, y las pérdidas humanas y materiales que está causando, nos ilustra en la práctica el desafío que para la sobrevivencia de la comunidad política centroamericana, y salvadoreña en particular, plantea el cambio climático. Aquí no me refiero únicamente al aumento de la temperatura del planeta sino a la condición de vulnerabilidad en la que vivimos los salvadoreños y las consecuencias políticas del vivir en esta situación ${ }^{18}$.

En los últimos cinco años varios fenómenos naturales se han traducido en desastres. Es el caso del huracán Mitch, los terremolos de enero y febrero del año en curso y la actual sequía. Es cierto que estos lenómenos son coyunturales y en cicrta forma inevitables. Además no todos se derivan del cambio climático. Pero el objetivo de tracr a cuenta aquí este tema es para volver la atención hacia cicrtas condiciones naturales que ponen en jaque el futuro de los salvadoreños. Condiciones naturales que van más allá de los problemas de contaminación, como el manejo de desechos sólidos, o de la tala de árboles y lo que ello significa para la caplación de agua.

Según una de las exposiciones en el seminario para el que lue preparado este diagnóstico, la comunidad política del estado salvadoreño necesita un territorio dos y media veces mayor que el aclual. Contamos con una capacidad biológica 
de $0.68 \mathrm{ha} /$ persona siendo que deberíamos tener una de $1.55 \mathrm{ha} /$ persona. Esto quiere decir que tenemos un déficit ecológico nacional de $0.87 \mathrm{ha}$ persona. La necesidad dê cubrir este déficit empuja a la búsqueda de diversos productos alimenticios fuera de las fronteras nacionales. El Salvador pareciera convertirse así en una especie de agujero negro en el espacio centroamericano. Buena parte de la producción de carne, leche y verduras, en Nicaragua, Honduras y Guatemala respectivamente, es chupada hacia el territorio salvadoreño. Este es un dato preocupante, pues cualquier conflicto con estos países puede tener repercusiones en la alimentación de las y los salvadoreños. Algo similar puede decirse respecto a la capacidad de abastecer de agua potable que tiene el país a sus habitantes. Y esto suponiendo que ANDA tuviese la capacidad para una cobertura total (cosa que no la tiene). Poco a poco, vamos avanzando hacia el norte del país en busca de fuentes de agua, y, tarde o temprano, tendremos que buscarla en Honduras'".

A este tipo de retos es que le he asociado una amenaza para la sobrevivencia de la comunidad política. Son problemas que tienen que ser enfrentados por los actores políticos, pues lo que está en juego es la posibilidad de vida en un futuro no muy lejano en este territorio. Por lo pronto, no parece que se esté tomando en serio este asunto. Ojalá que cuando se lo haga, no sea demasiado tarde. ¡Si es que no lo es ya!

\section{3. ¿Consolidación del actual régimen político?}

En realidad, muchas cosas más pueden decirse como diagnóstico político. No he tocado el tema de la violencia social, la inseguridad ciudadana, el funcionamiento de las instituciones del estado, etc., que también formarían parte de este retrato. Si no lo he hecho en parte se debe a la necesidad de enfatizar en otros aspectos sobre los cuales casi no se dice nada. Imagino que si hubiese tratado estos otros temas aquí la sensación de impotencia sería todavía más generalizada. ¡Y esto es muy peligroso! Al presentar este diagnóstico la intención ha sido más bien colaborar en el encuadre y definición de los ejes de acción de la Misión de la UCA desde una consideración lo más realista posible del contexto. En este sentido, deseo terminar volviendo sobre el tema del régimen político. Considero que las problemáticas planteadas son tales que no deben dejarse en las manos de los pocos que actualmente deciden el destino político salvadoreño. Esto significa dos cosas.

Por un lado, significa tomar postura por la democratización de la política. Que la toma de decisiones vinculantes adopte formas democráticas en donde el demos tenga un papel protagónico. Y esto lo digo, no desde una visión ingenua del asunto, como si el demos en su totalidad participará del proceso. No estoy planteando tomar postura en uno de los polos de la dicotomía democracia directa versus democracia representativa. Que el demos tenga un papel protagónico, no significa necesariamente participación directa en el momento de la toma de decisiones. Pero significa que los representantes (supuestos o no) no tengan manos libres para tomar decisiones irresponsables. $\mathrm{O}$, dicho de otra forma, fo- 
mentar los procesos de auditoría ciudadana en los diversos niveles de funcionamiento del aparato institucional del Estado ${ }^{21}$. Aquí hay todo un campo abierto para la imaginación política y en ello la lucidez académica puede contribuir en mucho.

Por otro lado, como agente socializador, la universidad ejerce una función de mediación entre la ciudadanía y las instituciones políticas. No dejar el protagonismo político a unos pocos (dado que las decisiones que adoptan afectan a todos y no necesariamente por igual) significa entonces que los procesos de socialización intrauniversitarios deben abrirse a la bidireccionalidad de dichos procesos. Y una mancra de hacer esto cs entrando al diálogo con otros agentes socializadores muy especialmente con los medios de comunicación de masas. Demostrado está que ćstos gozan de gran credibilidad entre la población y puede demostrarse cuánto intervienen en la formación de la agenda política nacional. Pues bien, creo que tampoco a los medios masivos de comunicación debe dejárseles sólos porque aunque medios son agentes políticos. Y, ante éstos, la inmensa mayoría de los ciudadanos puede estar indefensa e influenciable, a tal punto incluso de no querer saher nada de la política. ¡Justamente lo que los neoliberales desean!

\section{Referencias bibliográficas}

Castel Is, Manuel (1999). La era de la información. Economia, sociedad y cultura. Vol.l: La sociedad red. Madrid: Alianza.

Cerdas, Rodolfo (1995). "Los partidos políticos en Centroamérica y Panamá". En Perelli, C.: Picado, S. y Zovatto, D. (Comps.). Parridos y clase politica en América Latina en los 90, pp.3-28. San José, Costa Rica: Instituto Interamericano de Derechos Humanos-Centro de Capacitación Electoral.

Dahl, Robert (1989). La Poliarquía. Madrid: Tecnos.

Gućhenno, Jean-Marie (1995). El fin de la democracia. Barcelona: Paidós.

Huntington, Samuel (1994). La tercera ola. Barcelona: Paidós.

IUDOP. Encuestas de Opinión. Serie informes \# 46, 57,64, 69, 76, 80 y 86. San Salvador: Instituto Universitario de Opinión Pública.

Porras Nadales, Antonio (1996). "El orden comunicativo de la representación polílica", cn Porras Nadales, Antonio (Editor), El debate sobre la crisis de la representación política. Madrid: Tecnos, pp.149-190.

Rovira Mas, Jorge (1994). "El futuro de los partidos políticos en América Central". En Carballo Quintana, M. y Maihold, G. (Comps.). ¿Qué será de Centroamérica?: gobernabilidad, legitimidad electoral y sociedad civil, pp. 131-141. San José, Costa Rica: Fundación Friedrich Ebert.

Sobrino, Jon (1999). La fe en Jesucristo desde las victimas. San Salvador: UCA Editores. UCA (2001). Misión de la Universidad Centroamericana José Simeón Cañas. San Salvador: Universidad Centroamericana José Simeón Cañas.

\section{Notas}

1. El encuadre que poco a poco fue siendo definido por la mencionada comisión pareció a sus miembros bastante pesimista para el futuro de El Salvador. Fue motivo de discusión y reflexión la lorma cómo debía ser presentado el diagnóstico para no 
causar una sensación de impotencia pero no podíamos negar u ocultar lo que estabamos dibujando si queríamos contribuir a una definición realista de los Ejes de acción de nuestra Unizersidad. El día que se discutió en el seminario el diagnóstico preparado por la comisión no faltaron comentarios sobre lo pesimista que parecía la realidad dibujada. En varios grupos de discusión se hicieron apreciaciones semejantes y se insistió en la necesidad de apuntar algunos hechos positivos, esperanzadores para el futuro nacional. Sin embargo, también allí se hizo la reflexión sobre la necesidad de no ignorar u ocultar las dinámicas globales que amenazan el futuro del país para buscar, a partir de ellas, qué puede hacerse desde la Universidad para favorecer a quienes el documento de la Misión de la UCA define como el horizonte de su quehacer universitario: las mayorías (UCA, 2001:6).

2. Incluso llegué a sugerir que este tipo de reuniones para discutir dinámicas o procesos que caracterizan nuestra realidad nacional deberían realizarse con más frecuencia para evitar que el trabajo académico que realizamos al interior de la Universidad fuese hecho como en departamentos estancos. No sólo para estar informado de qué cosas realiza cada una de las unidades académicas sino justamente para no partir en nuestro trabajo de fragmentos de realidad. Es decir, para conocer y comprender mejor la totalidad de la realidad. Para aprehenderla, pues.

3. En este contexto, hablar de lo global y lo local tenía sus consecuencias epistemológicas y metodológicas pues suponía abandonar el tradicional análisis de lo externo y lo interno. Hablar de un Marco global condicionante no significa decir que lo externo condiciona lo interno. Lo global se hace presente al interior de cada país. Se maniliesta localmente según las particularidades. Esta es la razón por la cual nuestro segundo paso era identificar las dinámicas locales que traducían lo global. Nos ale jábamos así de la búsqueda de fenómenos y procesos internos.

4. Ahora podemos imaginarnos mejor cómo ciertas acciones locales pueden tener un sentido de solidaridad global. Antes se llevaban a cabo acciones locales de solidaridad con un determinado lugar. Así se constituyeron en varios lugares del mundo, por ejemplo, redes de solidaridad con El Salvador durante el conflicto armado. Se hablaba entonces se solidaridad internacional. Con este ejemplo puede verse cómo lo internacional no coincide con lo global. Lo internacional es entre naciones. Y éstas pueden ser dos o más. Lo global, para ser, debe cubrir todo el globo.

5. En realidad también aquí podría hablarse de un proceso global puesto que desde 1974, comenzando en Portugal, hasta la década de 1990, por los más variados puntos del globo terráqueo se llevaron a cabo transiciones políticas. Huntington (1994) llamó a este proceso global La tercera ola.

6. En parte, aquí reside el virtual éxito de la transición política salvadoreña al posibilitar la inexistencia de fuerzas políticas relevantes fuera del juego político. Mientras este acuerdo fundamental entre las élites políticas persista, el régimen instaurado no afrontará amenazas de quiebra. Por supuesto que esta situación puede darse incluso en un contexto de déficit de legitimidad creciente.

7. Utilizo la expresión demos como equivalente al opuesto a élites y con menor carga de valor negativa que el término masas.

8. Difícilmente podría haber sido de otra forma. El aprendizaje y adopción de nuevos canales de acción (democrática) tendría que ser algo posterior y quién sabe cuánto tiempo habría de tomar. Quizá hasta que haya un relevo generacional.

9. Digo principales actores políticos porque no son los únicos que se conformaron a partir del eje socialismo-capitalismo. Desde su muy temprana existencia, el socialis- 
mo fue identificado como comunismo y a partir de allí se articuló un discurso (ideología) anticomunista que sirvió de elemento cohesionador a prácticamente todos los partidos y grupos progobiernistas durante los regímenes militares del siglo $\mathrm{XX}$ en el país.

10. Como toda identidad fue fundamental el elemento diferenciador. En el caso salvadoreño, la negación del otro fue clave para forjar la propia identidad grupal. Esta negación fue fundamentalmente dialéctica traducida en posicionamientos anti.

11. Tan amargo es que para un sector del FMLN la lucha anticapitalista es algo a lo que no puede renunciar. Por lo menos en el discurso. Es normal. Cuanto más viejo se es (tanto individualmente como en cuanto actor político), más cuesta renunciar a aquello que le dio sentido a su vida durante mucho tiempo. Creo que aquí intervienen incluso factores psicológicos que hacen de la conversión no sólo un problema político sino incluso personal. Tal vez haya que esperar un cambio generacional para el abandono de este discurso o un cambio en el contexto internacional que le siga dando sentido al mismo.

12. Por supuesto que aquí se hipostasió lo estatal con lo público siendo que hay muchas cosas que siendo públicas no pasan por la acción del estado.

13. Lo cual los mismo neoliberales suelen interpretarlo como reducción del Estado porque para ellos "el problema es el Estado".

14. Lo cual significa que no importa tanto lo que se dice sino quién lo dice y cómo lo dice. No por gusto se dice que el nuevo político debe tener dotes de comunicador.

15. Proceso que podría notarse en el constante decir: "allá en los Estados Unidos las cosas son de otra manera", "dice mi hermano que en los Estados...", y en las nuevas pautas de comportamiento adquiridas "en el Norte".

16. Lo dicho está planteado cara a la Misión de la UCA. Pero también puede considerarse para cualquier alternativa política que se quiera implementar desde el aparato estatal. El imparable flujo migratorio y el efecto imán que los emigrados exitosos tienen sobre la potencial población migrante es comparable a un continuo flujo sanguíneo a través de una herida en el cuerpo. El lector puede pensar en los posibles escenarios que se derivan de una tal situación.

17. Y, por tanto, que plantean un problema de orden político.

18. Contribuye a esta condición de vulnerabilidad una diversidad de enfermedades (dengue hemorrágico, cólera, neumonía, etc.) que en más de alguna ocasión han obligado al gobierno a decretar estado de emergencia.

19. Si antes no se busca en el Pacífico con todo lo que implique de inversión para su tratamiento.

20. Con lo cual no estoy diciendo que sólo a ésta deba reducirse la participación ciudadana. Solamente digo que es necesario que existan mecanismo de control ciudadano sobre el comportamiento de los representantes. Cuáles sean esos mecanismos es algo que habría que discutir posteriormente, en la práclica. 